\title{
Anaemia Associated with Trypanosomes Infections in Cattle of West Gojjam Zone, Northwest Ethiopia
}

\author{
Kumela Lelisa (iD) and Behablom Meharenet $(\mathbb{D}$ \\ National Institute for the Control and Eradication of Tsetse Fly and Trypanosomosis, Akaki Kaliti Sub-City P.O. Box 19917, \\ Addis Ababa, Ethiopia \\ Correspondence should be addressed to Kumela Lelisa; lelisakumela@gmail.com
}

Received 8 January 2021; Revised 2 May 2021; Accepted 23 June 2021; Published 30 June 2021

Academic Editor: Fulvio Riondato

Copyright ( $\odot 2021$ Kumela Lelisa and Behablom Meharenet. This is an open access article distributed under the Creative Commons Attribution License, which permits unrestricted use, distribution, and reproduction in any medium, provided the original work is properly cited.

\begin{abstract}
Background. African animal trypanosomosis is a major veterinary problem over a large area of the tsetse belt region of Africa. Anaemia is a cardinal sign of trypanosome infections. The mechanism of anaemia due to trypanosomosis is complex and multifactorial in origin. Packed cell volume (PCV) usually gives an indication of the anaemia and disease status of a trypanosomeinfected animal. Methods. A cross-sectional study was conducted from December 2017 to January 2018 in West Gojjam zone, Northwest Ethiopia, to determine the trypanosome infections rate and the possible correlation between parasitic infection and anaemia using the dark ground buffy coat technique, Giemsa-stained thin blood smear, and PCV reading on a haematocrit reader. Results. The overall trypanosomosis prevalence was $7.81 \%, 95 \% \mathrm{CI}=7.45-8.17$. Trypanosoma congolense (4.25\%) and $\mathrm{T}$. vivax $(3.56 \%)$ were the trypanosomes species identified in the studied area. PCV for all sampled cattle was analysed to estimate the degree of anaemia. From the total examined animals $(N=730), 356(48.77 \%)$ were anaemic and $374(51.23 \%)$ were nonanaemic. The mean PCV of parasitemic cattle was significantly lower $(21.09 \%, 95 \% \mathrm{CI}=20.13-22.05)$ than that of aparasitemic ones $(25.96 \%, 95 \% \mathrm{CI}=25.68-26.24)$. There was a positive association between trypanosome infection and anaemia. Although both trypanosome species are significantly associated with a decreased herd mean PCV $(<24)$, the mean PCV of cattle infected with T. congolense (19.45\%) was lower than that of infected with T. vivax (23.04\%). The herd mean PCV was not significantly associated to locations, age, and sex of the studied animals. Conclusions. The study confirms that the prevalence of trypanosomes infections and herd mean PCV has a significant association. The mean herd PCV can be a useful cheap tool to screen for possible trypanosome infection. However, there were cattle positive for trypanosomes having mean PCV within the reference interval and negative animals with anaemia. Furthermore, PCV reading should be confirmed by other diagnostic techniques to accurately conclude that trypanosomosis is the only cause of anaemia.
\end{abstract}

\section{Introduction}

African animal trypanosomosis is a major veterinary problem over a large area of the tsetse belt region of Africa. It is a chronically debilitating protozoan disease of livestock, which is of great economic importance in sub-Saharan Africa. Six trypanosomes species were reported in Ethiopia, although the vascular trypanosomes $T$. congolense and T. vivax are the most pathogenic, economically very important, and widely distributed in the country $[1,2]$.

The trypanosomes that cause this disease are extracellular protozoan parasites that have developed efficient immune escape mechanisms to manipulate the entire host immune response to allow parasite survival and transmission. Anaemia is a cardinal sign of trypanosome infections [3]. The mechanism of anaemia due to trypanosomosis is complex and multifactorial in origin [4]. The rate at which anaemia develops is influenced by energy intakes and protein gain [5].

The interplay of several factors acting either individually or synergistically contributes to the development of haemolytic anaemia in human and animal trypanosomosis. Most common among these factors are increased intravascular red blood cells destruction caused by lashing action of trypanosome flagella, undulating pyrexia, platelet 
aggregation, toxins and metabolites from trypanosomes, lipid peroxidation, and malnutrition. Meanwhile, idiopathic serum and tumour necrosing factors are responsible for dyserythropoieses [6].

PCV usually gives an indication of the anaemia and disease status of a trypanosome-infected animal and is correlated with animal production and reproduction performance. Reports indicated that the prevalence of trypanosome infections and herd mean PCV has a relationship. PCV is expected to decrease with the increasing prevalence of trypanosomosis. Hence, the relationship between the prevalence of trypanosomes infections and herd mean PCV could be a useful tool in the management of trypanosomosis and planning of its control. However, this relationship has not been quantified in Northwest Ethiopia, specifically West Gojjam zone. Therefore, this study aimed at determining the relationship between trypanosomes infection rates and occurrence of anaemia and estimating the prevalence of bovine trypanosomosis in West Gojjam zone, Northwest Ethiopia.

\section{Methods}

2.1. Study Area Description. West Gojjam zone is bordered on the south by the Abay River, which separates it from Oromia and Benishangul Gumuz regions, on the west by Awi zone, on the northwest by Northern Gondar, on the north by Lake Tana and the Abay River that separates it from South Gondar, and on the east by East Gojjam. The study was conducted in Debub Achefer and Semen Achefer (Figure 1). The area of the zone is 13,312 square kilometres.

The climate of the area is tropical. The annual mean temperature in West Gojjam ranges $12.9-29.5^{\circ} \mathrm{C}$. The area is characterized by a mixed type of farming systems. The climate alternates with long summer rainfall (June-September) and winter dry season (October-May) with mean annual rainfall [7]. The mean annual rainfall in the West Gojjam is 1352.9 millilitres. The cattle in the study areas are local indigenous zebu breed that are kept under traditional extensive husbandry systems with communal herding.

2.2. Study Design and Sampling Methods. A cross-sectional study was conducted from December 2017 to January 2018 to determine the relationship between trypanosomes infection rates and occurrence of anaemia and to estimate the prevalence of bovine trypanosomosis in West Gojjam zone, Northwest Ethiopia. Two districts, Debub Achefer and Semen Achefer, were purposively selected based on farmers' complaints of trypanosomosis problems. Then, the study sites were selected based on the accessibility of roads and the availability of sampling animals. Simple random sampling was employed to select individual study animals. The age of study animals was estimated based on dentition techniques given by De Lahunte and Habel [8] and information from owners. The sample size was determined considering 50\% expected prevalence and 5\% absolute desired precision at $95 \%$ confidence level based on the formula given by Thrusfield [9]. Accordingly, 384 study animals were needed; however, the sample from 730 cattle were collected, processed, and examined.
2.3. Blood Sampling and Examination. Paired blood samples were collected by puncturing the marginal ear vein of each animal into heparinized microhaematocrit capillary tubes (Deltalab SL, Barcelona, Spain). After sealing one end of capillary tubes with crystal sealant (Hawksley Ltd., Lancing, United Kingdom (UK)), samples were centrifuged using a microhematocrit centrifuge (Hawksley and Sons, UK) at 12000 revolutions per minute for 5 minutes. Anaemia was estimated by measuring PCV using the haematocrit reader. Animals with PCV less than $24 \%$ were considered anaemic, and the mean PCV between $24 \%$ and $48 \%$ was considered as normal threshold [10-12]. The contents of the capillary tubes including about $1 \mathrm{~mm}$ above and below the buffy coat were smeared on microscopic slides, covered with $22 \times \times 22$ cover slips, and examined under a $\times 40$ objective of microscope using a dark ground buffy coat technique to detect the presence of motile trypanosomes. For positive samples, Giemsa stain of thin blood smears were made, fixed with methanol for 5 minutes, and examined under oil immersion using $\times 100$ objective to identify the species of trypanosomes based on morphological characteristics [13].

2.4. Data Analysis. All statistical analyses were performed using STATA software version 12 (Stata Corporation, Texas, USA). The prevalence was calculated for all data as the number of infected individuals divided by the number of individuals examined and multiplied by 100 . The association between trypanosome infection and anaemia (PCV <24\%) was assessed by the chi-square test. The associations between the prevalence of trypanosomosis and associated risk factors such as districts, age groups, and sexes were assessed by the chi-square $\left(\chi^{2}\right)$ test, whereas the $t$-test (two-group mean comparison test) was used to assess the difference in the mean PCV between trypanosome positive and negative animals, the trypanosome species, sex, and age groups. A statistically significant association between variables was said to exist if the $P$ value is $<0.05$ at $95 \%$ confidence level.

\section{Results}

3.1. Parasitological Findings. The overall trypanosomosis prevalence was $7.81 \%$ and $95 \% \mathrm{CI}=7.45-8.17$, in the studied area. Trypanosome infection was not associated with geographical district, age, or sex of the animals (Table 1).

3.2. Haematological Findings. The mean PCV of all examined cattle was $25.58 \pm 3.95$. The mean PCV in trypanosome positive $(21.09 \%)$ and negative $(25.96 \%)$ was significantly different (Table 2).

From the total $n=730$ examined animals, $356(48.77 \%)$ had a mean PCV below the reference interval (PCV <24\%) and $374(51.23 \%)$ had a mean PCV within the reference interval (24-48\%); the infection was significantly associated with the anaemic state (Table 3). The mean PCV of cattle infected with $T$. congolense is lower than $T$. vivax. No difference in the PCV value was detected between male and female cattle and between young and adult cattle (Table 4). 


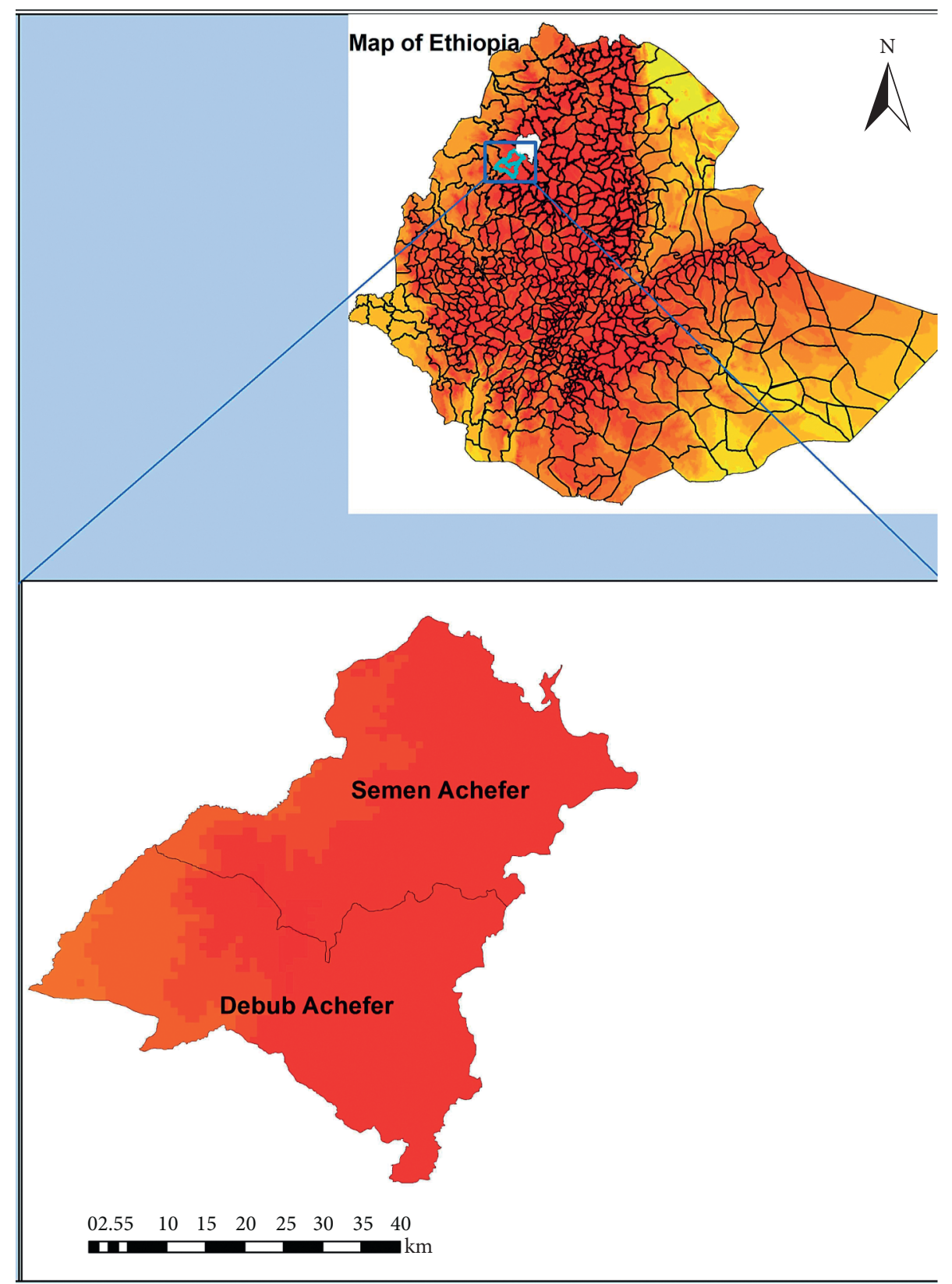

Elevation (m)
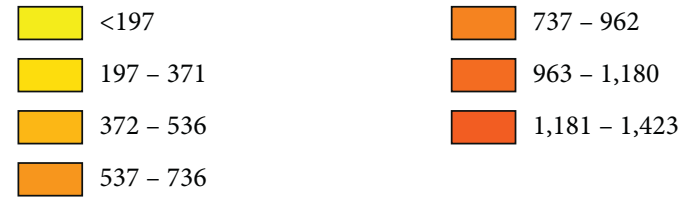

$1,424-1,774$

$1,775-2,338$

$2,339-5,780$

FIGURE 1: Map showing the geographical location of the study sites in Northwest Ethiopia.

\section{Discussion}

The study was conducted from December 2017 to January 2018 in West Gojjam zone, Northwest Ethiopia. The overall prevalence of bovine trypanosomosis in the studied area was $7.81 \%$ and $95 \% \mathrm{CI}=7.45-8.17$. This value was in line with the reports of Abebe et al. [14] who reported trypanosome prevalence of $7.80 \%$ in Omo-Ghibe tsetse fly belt, South Ethiopia, and Tafese et al. [15] in East Wollega zone who reported trypanosomosis prevalence of $8.50 \%$. The result of the current study was lower than a range of studies conducted previously in Ethiopia. Mekuria and Gadissa [16] reported $12.41 \%$ trypanosomosis prevalence in Metekel and Awi zones of Northwest Ethiopia and Afework et al. [17] in 
TABLE 1: The prevalence of trypanosomosis and associated risk factors.

\begin{tabular}{lccc}
\hline Risk factors & No. of examined $(=N)$ & No. of positive & $\chi^{2}$ \\
\hline Districts & & & $P$ value \\
$\quad$ Debub Achefer & 420 & $36(8.57 \%)$ & 0.80 \\
$\quad$ Semen Achefer & 310 & $21(6.77 \%)$ & 0.71 \\
\hline Age & 372 & $27(7.26 \%)$ & 0.32 \\
$\quad$ Young & 358 & $30(8.38 \%)$ & 0.57 \\
$\quad$ Adult & 408 & $29(7.11 \%)$ & 0.63 \\
\hline Sex & 322 & $28(8.70 \%)$ & 0.43 \\
$\quad$ Female & & & \\
$\quad$ Male & & & \\
\hline
\end{tabular}

TABle 2: The mean PCV of positive and negative cattle for trypanosomosis examined in West Gojjam, Northwest Ethiopia.

\begin{tabular}{lccccc}
\hline Group & Number examined & Mean & Standard error & Standard deviation & 95\% confidence level \\
\hline Negative & 673 & 25.96 & 0.14 & 3.73 & $25.68-26.24$ \\
Positive & 57 & 21.09 & 0.48 & 3.63 & $20.13-22.05$ \\
Total & 730 & 25.58 & 0.15 & 3.95 & $25.29-25.86$ \\
\hline
\end{tabular}

$|t|=9.48 ; P \leq 0.001 ; \mathrm{DF}, 728 ; \mathrm{DF}$, degree of freedom.

TABLE 3: Association of trypanosomes infection and the occurrence of anaemia.

\begin{tabular}{lcccc}
\hline Status & Noninfected & Infected & Total & $x^{2}$ \\
\hline Anaemic $(\mathrm{PCV}<24 \%)$ & $307(86.24 \%)$ & $49(13.76 \%)$ & $356(48.77 \%)$ & 34.24 \\
Nonanaemic $(\mathrm{PCV} \geq 24 \%)$ & $366(97.86 \%)$ & $8(2.14 \%)$ & $374(51.23 \%)$ & $\leq 0.001$ \\
Total & $673(92.19 \%)$ & $57(7.81 \%)$ & 730 & \\
\hline
\end{tabular}

TABLE 4: Comparison of the mean PCV of infected cattle in association with the trypanosome species, sex, and age groups.

\begin{tabular}{|c|c|c|c|c|c|c|}
\hline & Number of positives & Mean PCV (\%) & SE & $\mathrm{SD}$ & $95 \% \mathrm{CI}$ & $P$ value \\
\hline \multicolumn{7}{|c|}{ Trypanosome species } \\
\hline T. congolense & 31 & 19.45 & 0.54 & 3.02 & $18.34-20.56$ & $\leq 0.001$ \\
\hline T. vivax & 26 & 23.04 & 0.66 & 3.35 & $21.68-24.39$ & \\
\hline \multicolumn{7}{|l|}{ Sex } \\
\hline Male & 28 & 20.57 & 0.74 & 3.93 & $19.05-22.06$ & 0.29 \\
\hline Female & 29 & 21.59 & 0.61 & 3.30 & $20.33-22.84$ & \\
\hline \multicolumn{7}{|l|}{ Age } \\
\hline Young & 27 & 21.04 & 0.72 & 3.77 & $19.55-22.53$ & 0.92 \\
\hline Adult & 30 & 21.13 & 0.65 & 3.56 & $19.80-22.46$ & \\
\hline
\end{tabular}

CI, confidence interval; SD, standard deviation; SE, standard error.

Metekel district reported $17.20 \%$. Such variations may exist because of differences in agroclimates, distributions and density of vectors, season, and vectors control applications that may hinder the epidemiology of trypanosomosis.

Two Trypanosoma species, namely, T. congolense and T. vivax were identified in the studied area. These two trypanosomes species were also reported by Denbarga et al. [18] in the same studied area. Duguma et al. [19] and Cherinet et al. [20] also showed that these two trypanosomes species were encountered frequently in the country. T. congolense infection $(4.25 \%)$ was higher than that of T. vivax (3.56\%). This could be because the capacity of tsetse fly is probably more efficient in transmitting $T$. congolense than T. vivax [21]. Trypanosomosis prevalence was not significantly associated to districts, age, and sex of animals, which is in line with the report of Lelisa et al. [22] in West Ethiopia. Mulaw et al. [23] also described that there was no significant variation in trypanosomosis prevalence between sex and study sites in Northwest Ethiopia.

The mean PCV in trypanosome positive and negative cattle was 21.09 and $25.96 \%$, respectively. Similar values were reported by different authors. Biyazen et al. [24] reported a mean PCV value of 22.36 and $27.86 \%$ in parasitaemic and aparasitaemic animals, respectively, in Western Ethiopia. Dagnachew et al. [25] reported mean $24.29 \%$ in trypanosome positive and $27.46 \%$ in Northwest Ethiopia. Desta et al. [26] also reported a mean PCV of $22.96 \%$ and $25.46 \%$ in trypanosome positive and negative, respectively. Degneh et al. [27] reported a mean PCV of $20.48 \%$ and $25.77 \%$ in positive and negative cattle. Waisma and Katunguka- 
Rwakishaya [28] reported $22.3 \%$ and $29.0 \%$ mean PCV in positive and negative cattle, respectively, in southwestern Uganda.

The mean PCV value in trypanosome-infected cattle was significantly lower than in the noninfected cattle population. Furthermore, as the development of anaemia is one of the cardinal signs of trypanosomosis [29], PCV decrease with the increasing prevalence of trypanosomosis is expected. The intensity of anaemia evidenced by declining PVC values was reported to be an indicator of the severity of trypanosomosis and correlates with the loss of production performance in susceptible or infected animals [6, 30-34].

However, there were anaemic cattle that were not infected with trypanosomes that would be due to clearance of the parasites from circulation with trypanocidal drugs and inadequacy of detection methods used (dark ground buffy coat technique). In addition, other factors, alone or in combinations, may induce anaemia in absence of trypanosomosis. Fasciolosis and gastrointestinal parasites that cause haemorrhagic anaemia, blood parasites $[35,36]$, and other diseases that cause erythrocyte haemolysis or specific nutritional deficiencies [37] may result in occurrence of anaemia.

The occurrence of positive animals with PCV of greater than $24 \%$ might be as a result of recent infection and may be due to animals that tolerated parasitaemia without showing anaemia [38]. There was no previous report on the multifactorial anaemia in the studied area, and their contribution cannot be ruled out. The current study indicated that PCV alone could not be utilized as a tool to diagnose trypanosomosis and agreed with the findings of Coetzer et al. [39] and Van den Bossche and Rowlands [40] who indicated measuring PCV could be not a confirmatory for diagnosis of trypanosomosis.

Both T. congolense and T. vivax were associated with lower PCV. Awa and Ndamkou [41] also showed that the mean PCV value was significantly affected by both T. congolense and T. vivax. PCV was significantly affected by trypanosome species. Cattle infected with $T$. congolense had a mean PCV lower than that infected with T. vivax. Sekini et al. [42] indicated that $T$. congolense is more pathogenic than T. vivax and cause severe parasitaemia and anaemia. In contrast to this finding, Achukwi and Musongong [43] showed that PCV is not affected by trypanosome species.

The occurrence of anaemia between the districts, age, and sex groups was not significant. This finding was in agreement with the report that revealed Ethiopian cattle breed of any sex and age did not show a significant difference in anaemia prevalence [44].

\section{Conclusions}

The prevalence of bovine trypanosomosis was 7.18\%. Trypanosome infection and the anaemic state has a significant association Nevertheless, since there were animals that were positive for trypanosomes having mean PCV within the normal threshold and negative animals with anaemia, measuring PCV alone cannot be a confirmatory for diagnosis of trypanosomosis.

\section{Data Availability}

The datasets that support the findings of this study are available from the corresponding author upon request.

\section{Ethical Approval}

The National Institute for the Control and Eradication of Tsetse Fly and Trypanosomosis, Ministry of Agriculture, Ethiopia, authorized the fieldwork.

\section{Consent}

The purpose of the study was clearly explained to the cattle owners ' and veterinary officers and informed consents were obtained through verbal consent from Institute Technique Committee.

\section{Conflicts of Interest}

The authors declare that they no conflicts of interest.

\section{Authors' Contributions}

Both Kumela Lelisa and Behablom Meharenet contributed equally to this work.

\section{References}

[1] B. Stijlemans, P. De Baetselier, S. Magez, J. A. Van Ginderachter, and C. De Trez, "African trypanosomiasis-associated anemia: the contribution of the interplay between parasites and the mononuclear phagocyte system," Frontiers in Immunology, vol. 9, p. 218, 2018.

[2] G. J. Losos and B. O. Ikede, "Review of pathology of diseases in domestic and laboratory animals caused by Trypanosoma congolense, T. vivax, T. brucei, T. rhodesiense and T. gambiense," Veterinary Pathology, vol. 9, no. 1_suppl, pp. 1-79, 1972.

[3] P. H. Holmes, E. Katunguka-Rwakishaya, J. J. Bennison, G. J. Wassink, and J. J. Parkins, "Impact of nutrition on the pathophysiology of bovine trypanosomiasis," Parasitology, vol. 120, no. 7, pp. 73-85, 2000.

[4] J. Naessens, H. Kitani, Y. Nakamura, Y. Yagi, K. Sekikawa, and F. Iraqi, "TNF-alpha mediates the development of anaemia in a murine Trypanosoma brucei rhodesiense infection, but not the anaemia associated with a murineTrypanosoma congolense infection," Clinical and Experimental Immunology, vol. 139, no. 3, pp. 405-410, 2005.

[5] J. Cnops, C. De Trez, B. Stijlemans et al., "NK-, NKT-and CD8-derived IFN $\gamma$ drives myeloid cell activation and erythrophagocytosis, resulting in trypanosomosis-associated acute anemia," PLoS Pathogens, vol. 11, no. 6, Article ID e1004964, 2015.

[6] O. O. Akinbamijo, J. J. Bennison, J. Jaitner, and L. Dempfle, "Haematological changes in N'Dama and Gobra Zebu bulls during Trypanosoma congolense infection maintained under a controlled feeding regimen," Acta Tropica, vol. 69, no. 3, pp. 181-192, 1998.

[7] L. Tadesse, K. V. Suryabhagavan, G. Sridhar, and G. Legesse, "Land use and land cover changes and soil erosion in yezat watershed, north western Ethiopia," International Soil and Water Conservation Research, vol. 5, no. 2, pp. 85-94, 2017. 
[8] A. D. Lahunta and R. E. Habel, Applied Veterinary Anatomy, WB Saunders, Philadelphia, PA, USA, 1986.

[9] M. Thrusfield and R. Christley, Veterinary Epidemiology, Wiley Online Library, Hoboken, NJ, USA, 9600 ed edition, 2005.

[10] G. d'Ieteren and K. Kimani, "Indigenous genetic resources: a sustainable and environmentally friendly option for livestock production in areas at risk from trypanosomes," Science in Africa, vol. 1, 2001.

[11] A. M. Erkelens, R. H. Dwinger, B. Bedane, J. H. W. Slingenbergh, and W. Wint, "Selection of priority areas for tsetse control in Africa; a decision tool using GIS in Didessa Valley, Ethiopia, as a pilot study," in Animal Trypanosomosis: Diagnosis and Epidemiology. Results of a FAO/ IAEA Co-Ordinated Research Programme on the Use of Immunoassay Methods for Improved Diagnosis of Trypanosomosis and Monitoring Tsetse and Trypanosomosis Control Programmes, International Atomic Energy Agency, Vienna, Austria, 2000.

[12] A. Kessell, "Bovine haematology and biochemistry," in Bovine Medicine, Peter D. Cockcroft, Ed., John Wiley \& Sons, Ltd, Hoboken, NJ, USA, pp. 146-160, 2015.

[13] M. Murray, P. K. Murray, and W. I. M. McIntyre, "An improved parasitological technique for the diagnosis of African trypanosomiasis," Transactions of the Royal Society of Tropical Medicine and Hygiene, vol. 71, no. 4, pp. 325-326, 1977.

[14] R. Abebe, S. Gute, and I. Simon, "Bovine trypanosomosis and vector density in Omo-Ghibe tsetse belt, South Ethiopia," Acta Tropica, vol. 167, pp. 79-85, 2017.

[15] W. Tafese, A. Melaku, and T. Fentahun, "Prevalence of bovine trypanosomosis and its vectors in two districts of East Wollega Zone, Ethiopia," Onderstepoort Journal of Veterinary Research, vol. 79, no. 1, pp. 1-4, 2012.

[16] S. Mekuria and F. Gadissa, "Survey on bovine trypanosomosis and its vector in Metekel and Awi zones of Northwest Ethiopia," Acta Tropica, vol. 117, no. 2, pp. 146-151, 2011.

[17] Y. Afewerk, P.-H. Clausen, G. Abebe, G. Tilahun, and D. Mehlitz, "Multiple-drug resistant Trypanosoma congolense populations in village cattle of Metekel district, northwest Ethiopia," Acta Tropica, vol. 76, no. 3, pp. 231-238, 2000.

[18] Y. Denbarga, O. Ando, and R. Abebe, "Trypanosoma species causing bovine trypanosomosis in south Achefer District, Northern Ethiopia," Journal of Veterinary Advance, vol. 2, no. 2, pp. 108-113, 2012.

[19] R. Duguma, S. Tasew, A. Olani et al., "Spatial distribution of glossina sp. and trypanosoma sp. in south-western Ethiopia," Parasites \& Vectors, vol. 8, no. 1, p. 430, 2015.

[20] T. Cherenet, R. A. Sani, N. Speybroeck, J. M. Panandam, S. Nadzr, and P. Van den Bossche, "A comparative longitudinal study of bovine trypanosomiasis in tsetse-free and tsetse-infested zones of the Amhara Region, northwest Ethiopia," Veterinary Parasitology, vol. 140, no. 3-4, pp. 251-258, 2006.

[21] S. Leta, G. Alemayehu, Z. Seyoum, and M. Bezie, "Prevalence of bovine trypanosomosis in Ethiopia: a meta-analysis," Parasites and Vectors, vol. 9, no. 1, p. 139, 2016.

[22] K. Lelisa, S. Shimeles, J. Bekele, and D. Sheferaw, "Bovine trypanosomosis and its fly vectors in three selected settlement areas of Hawa-Gelan district, Western Ethiopia," Onderstepoort Journal of Veterinary Research, vol. 81, no. 1, pp. 1-5, 2014.

[23] S. Mulaw, M. Addis, and A. Fromsa, "Study on the prevalence of major trypanosomes affecting bovine in tsetse infested
Asosa District of Benishangul Gumuz Regional State, Western Ethiopia," Global Veterinaria, vol. 7, no. 4, pp. 330-336, 2011.

[24] H. Biyazen, R. Duguma, and M. Asaye, "Trypanosomosis, its risk factors, and anaemia in cattle population of Dale Wabera District of Kellem Wollega Zone, Western Ethiopia," Journal of Veterinary Medicine, vol. 2014, Article ID 374191, 6 pages, 2014.

[25] S. Dagnachew, H. Girma, and G. Abebe, "A cross-sectional study on bovine trypanosomosis in Jawi district of Amhara Region, Northwest Ethiopia," Ethiopian Veterinary Journal, vol. 15, 2011.

[26] M. Desta, D. Beyene, and S. Haile, "Trypanosome infection rate of Glossina pallidipes and trypanosomosis prevalence in cattle in Amaro Special District of Southern Ethiopia," Journal of Veterinary Medicine and Animal Health, vol. 5, no. 6, pp. 164-170, 2013.

[27] E. Degneh, W. Shibeshi, G. Terefe, K. Asres, and H. Ashenafi, "Bovine trypanosomosis: changes in parasitemia and packed cell volume in dry and wet seasons at Gidami District, Oromia Regional State, Western Ethiopia," Acta Veterinaria Scandinavica, vol. 59, no. 1, pp. 1-8, 2017.

[28] C. Waiswa and E. Katunguka-Rwakishaya, "Bovine trypanosomiasis in south-western Uganda: packed-cell volumes and prevalences of infection in the cattle," Annals of Tropical Medicine \& Parasitology, vol. 98, no. 1, pp. 21-27, 2004.

[29] T. Marcotty, H. Simukoko, D. Berkvens, J. Vercruysse, N. Praet, and P. Van den Bossche, "Evaluating the use of packed cell volume as an indicator of trypanosomal infections in cattle in eastern Zambia," Preventive Veterinary Medicine, vol. 87, no. 3-4, pp. 288-300, 2008.

[30] S. Tasew and R. Duguma, "Cattle anaemia and trypanosomiasis in western Oromia State, Ethiopia," Revue de Médecine Vétérinaire, vol. 163, no. 12, pp. 581-588, 2012.

[31] M. Murray and T. M. Dexter, "Anaemia in bovine African trypanosomiasis. a review," Acta Tropica, vol. 45, pp. 389-432, 1988.

[32] C. C. Ohaeri and M. C. Eluwa, "Abnormal biochemical and haematological indices in trypanosomiasis as a threat to herd production," Veterinary Parasitology, vol. 177, no. 3-4, pp. 199-202, 2011.

[33] J. C. M. Trail, G. D. M. d'Teteren, A. Feron, O. Kakiese, M. Mulungo, and M. Pelo, "Effect of trypanosome infection, control of parasitaemia and control of anaemia development on productivity of N'Dama cattle," Acta Tropica, vol. 48, no. 1, pp. 37-45, 1990.

[34] J. C. Trail, G. D. d'Ieteren, M. Murray et al., "Measurement of trypanotolerance criteria and their effect on reproductive performance of N'Dama cattle," Veterinary Parasitology, vol. 45, no. 3-4, pp. 241-255, 1993.

[35] T. Sitotaw, F. Regassa, F. Zeru, and A. G. Kahsay, "Epidemiological significance of major hemoparasites of ruminants in and around Debre-Zeit, Central Ethiopia," Journal of Parasitology and Vector Biology, vol. 6, no. 2, pp. 16-22, 2014.

[36] J. W. Magona and J. S. P. Mayende, "Occurrence of concurrent trypanosomosis, theileriosis, anaplasmosls and helminthosis in Friesian, Zebu and Sahiwal cattle in Uganda," Onderstepoort Journal of Veterinary Research, vol. 69, no. 2, pp. 133-140, 2002.

[37] O. M. Radostitis, C. C. Gay, K. W. Hinchcliff, and P. Contable, Veterinary Medicine: A Textbook of the Diseases of Cattle, Horses, Pigs, Sheep and Goat, Elsevier Saunders, Philadelphia, PA, USA, 2007.

[38] G. J. Rowlands, W. Mulatu, S. M. Nagda, and G. D. M. d'Ieteren, "Variations in packed red cell volume and 
trypanosome prevalence and relationships with reproductive traits in East African Zebu cows exposed to drug-resistant trypanosomes," Acta Tropica, vol. 59, no. 2, pp. 105-116, 1995.

[39] J. A. W. Coetzer, G. R. Thomson, and R. C. Tustin, "Infectious diseases of livestock with special reference to Southern Africa," Journal of the South African Veterinary Association, vol. 66, no. 2, p. 106, 1995.

[40] P. Van den Bossche and G. J. Rowlands, "The relationship between the parasitological prevalence of trypanosomal infections in cattle and herd average packed cell volume," Acta Tropica, vol. 78, no. 2, pp. 163-170, 2001.

[41] D. N. Awa and C. N. Ndamkou, "Response of Trypanosoma vivax and Trypanosoma congolense in zebu cattle in North Cameroon to prophylactic treatment with two formulations of isometamidium," Preventive Veterinary Medicine, vol. 76, no. 1-2, pp. 90-96, 2006.

[42] V. O. Sekoni, D. I. Saror, C. O. Njoku, J. Kumi-Diaka, and G. I. Opaluwa, "Comparative haematological changes following Trypanosoma vivax and T. congolense infections in Zebu bulls," Veterinary Parasitology, vol. 35, no. 1-2, pp. 11-19, 1990.

[43] M. D. Achukwi and G. A. Musongong, "Trypanosomosis in the Doayo/Namchi (bos Taurus) and zebu white fulani (bos indicus) cattle in faro division, north Cameroon," Journal of Applied Biosciences, vol. 15, pp. 807-814, 2009.

[44] J. Stein, "Trypanotolerance and phenotypic characteristics of four Ethiopian cattle breeds," Ph.D. thesis, Acta Universitatis Agriculturae Sueciae, Uppsala, Sweden, 2011. 